\title{
The Effect of Layer Variation Between Liner and Cement Mantle on Reducing Cracks of PMMA Material Hip Joints
}

\author{
Eko Saputra ${ }^{1,2, *}$, Jamari $^{1}$, Han Ay Lie ${ }^{3}$, Iwan Budiwan Anwar ${ }^{4}$, Rifky Ismail ${ }^{1}$, Mohammad Tauviqirrahman ${ }^{1}$, \\ Emile van der Heide ${ }^{2}$ \\ ${ }^{1}$ Department of Mechanical Engineering, Engineering Faculty, Diponegoro University, Semarang - Indonesia \\ ${ }^{2}$ Laboratory for Surface Technology and Tribology, Engineering Technology Faculty, Twente University, Enschede - The \\ Netherlands \\ ${ }^{3}$ Department of Civil Engineering, Engineering Faculty, Diponegoro University, Semarang - Indonesia \\ ${ }^{4}$ Orthopaedic and Traumatology Department, Prof. dr. R. Soeharso Orthopaedic Hospital, Surakarta - Indonesia
}

\begin{abstract}
Failure of cement mantle of bond loosening between liner and cement mantle is an important issue in total hip replacement. Two factors that commonly cause cement mantle failure are initial crack and stress. A solution for reducing stress on the cement mantle has been proposed by adding insertion material between liner and cement mantle. Nevertheless, further study is needed to optimize the proposed solution. A possible option is to vary the thickness of the insertion material. If the thickness of the PMMA material is constant, then the variation of the insertion thickness will be followed by the variation of the thickness of the liner. Consequently, the stress value on the liner will follow the variation of liner thickness. The objective of this study is to examine the effect of the thickness variation of the insertion material to stress on cement mantle and liner using finite element simulation. Results revealed that the magnitude of stress and deflection decreased in the cement mantle and the liner along with the increasing thickness of the insertion material.
\end{abstract}

Keywords: Cement mantle; liner; PMMA; hip joint; crack, stress.

\section{Introduction}

Implant material of bone cement or cement mantle is widely used to affix hip prosthesis in the total hip replacement [1]. Cement mantle experiences repeated cyclic loading, which can lead to fracture or crumble of the cement mantle [2]. The cement mantle failure is often associated with cracking in the cement mantle [3]. Cracking in the cement mantle is affected by material defects cause initial cracks, less than optimal thickness of the cement mantle, and stress on the cement mantle due to a contact load that can increase an initial crack. Cracking problem can be investigated by experimental fatigue testing and computer simulations [3, 4]. To reduce the stress on the cement mantle with increase in the thickness of cement mantle, a number of researchers have attempted to optimize the cement mantle $[1,5,6]$. The conclusion of these studies is that stress on the cement mantle can be reduced by the reinforcement of cement mantle. However, Mann et al. stated that the growth rate of fatigue cracks did not depend on the thickness of cement mantle [7, 8].

Recently, Jamari et al. argued that increasing the thickness of cement mantle only affected the strength of the cement mantle itself, but not reduction in the cyclic load directly on the cement mantle [9]. The effect of cyclic loading or in other words can be represented by repeated load can lead failure of hip prosthesis [10-12]. Furthermore, Jamari and colleagues argued that before the cyclic load toward the cement mantle, an additional layer was necessary. This layer is expected to reduce the contact stress on cement mantle and also the cyclic load toward the cement material. Therefore, Jamari et al. proposed the layer addition to decrease the stress on the cement mantle. The results showed that the layer addition was able to decrease the stress on the cement mantle. Then the question arises: how optimal layer thickness to reduce stress on the cement mantle? The objective of this research is to investigate the optimal thickness of layer addition. For this purpose, the finite element simulation of contact static was performed using Abaqus software.

\section{Material and Method}

\subsection{Geometry and material properties}

The cemented consist of stem, ball (head), liner, cement, and acetabulum (Figure 1). Figure 1(b) shows the arrangement of hip interaction contact among the ball, liner, cement mantle, and bone. To simplify the analysis, an axisymmetric model was considered. The ball diameter, and the bone diameter were $28 \mathrm{~mm}$ and

Corresponding author: ekosaputro984@gmail.com 
$60.2 \mathrm{~mm}$. The thickness of cement mantle used in this simulation adopted the research by Gun et al. [10]. Meanwhile, the liner thickness had five variations, see Table 1.

Table 1. The thickness variation of layer and liner

\begin{tabular}{|c|c|c|}
\hline Thickness & Layer [mm] & Liner [mm] \\
\hline $\mathrm{T}(1)$ & 0.5 & 6.5 \\
\hline $\mathrm{T}(2)$ & 1 & 6 \\
\hline $\mathrm{T}(3)$ & 1.5 & 5.5 \\
\hline $\mathrm{T}(4)$ & 2 & 5 \\
\hline $\mathrm{T}(5)$ & 2.5 & 4.5 \\
\hline
\end{tabular}

Table 2 summarizes the material properties of components were used in this simulation. The cortical bone, polymethyl methacrylate (PMMA), ultra high molecular weight poly-ethylene (UHMWPE), and stainless steel $316 \mathrm{~L}$ were determined as material properties for the bone, cement mantle, liner, and ball, respectively.

Table 2. Material properties

\begin{tabular}{|l|c|c|}
\hline \multicolumn{1}{|c|}{ Materials } & $\begin{array}{c}\text { Modulus } \\
\text { elasticity (MPa) }\end{array}$ & $\begin{array}{c}\text { Poisson's } \\
\text { ratio }\end{array}$ \\
\hline Cement [14 - 16] & $2000-2300$ & 0.3 \\
\hline Bone [13 - 15] & 17,000 & 0.3 \\
\hline UHMWPE [15 - 17] & $690-945$ & 0.45 \\
\hline SS316L [18] & 193,000 & 0.3 \\
\hline
\end{tabular}

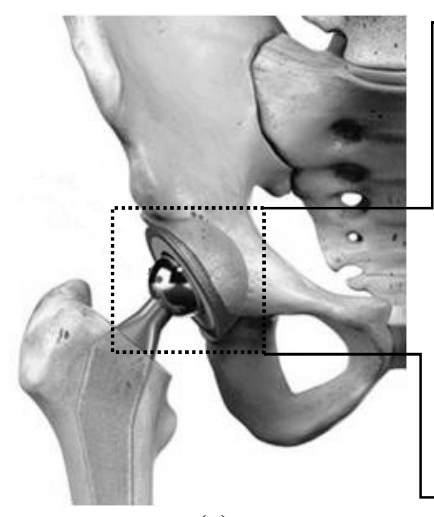

(a)

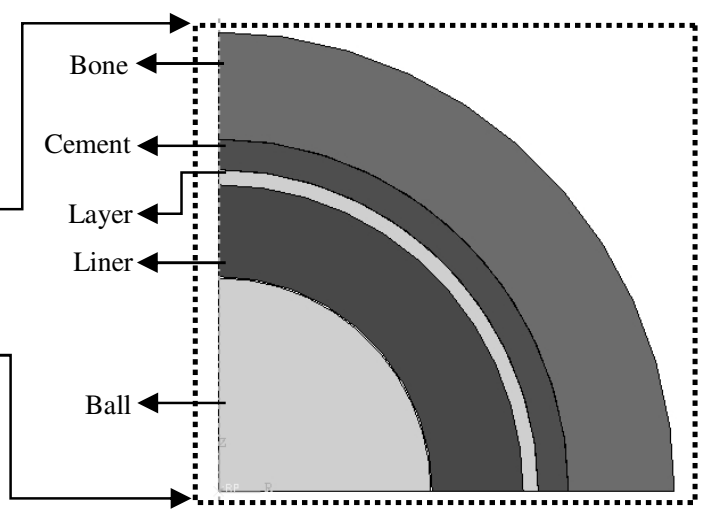

(b)

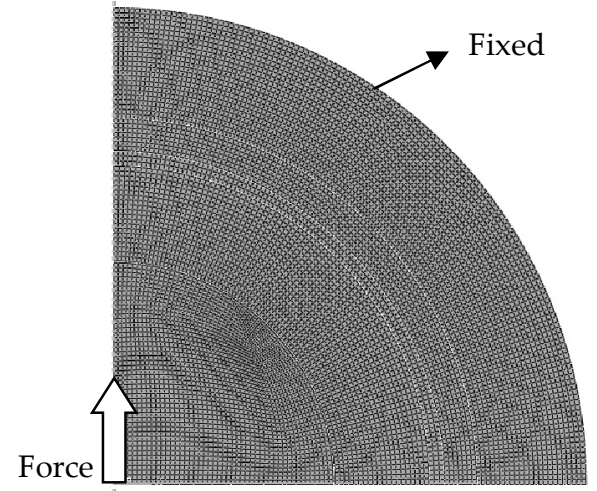

(c)

Fig. 1. (a) Cemented hip prosthesis [9], (b) geometry model with layer and (c) applied load, boundary conditions, and mesh

\subsection{Simulation Procedure}

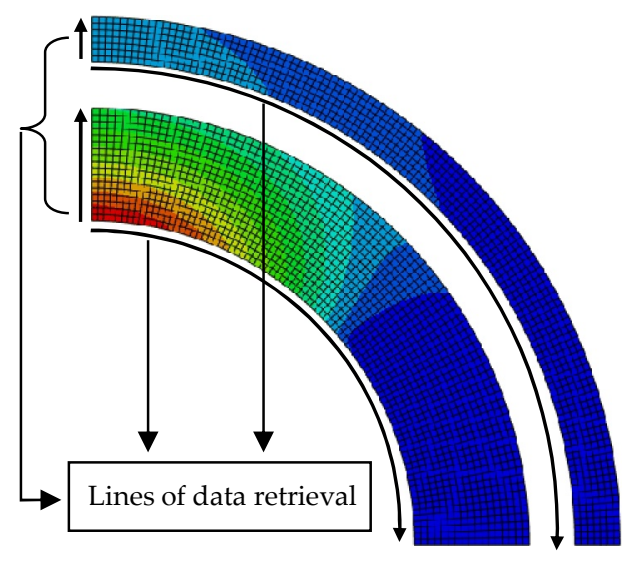

(a)

Fig. 2. Lines of data retrieval for (a) liner and (b) PMMA

To generate stresses in the cement mantle and liner, static contact simulation was performed. To simulate this case, the Abaqus Software was selected [19]. The applied load of force to the centre of ball was $3000 \mathrm{~N}$ [20]. The boundary conditions were applied on the left side of the model, whereas the bone model was fixed on the outer surface. The interaction of contact occured only on the surface of ball against the surface of inner liner, whereas the others were tied. The mesh used in this simulation was 4-node bilinear axisymmetric

(CAX4R). The element and node numbers were 8236 and 8724 respectively.

In this study, the contact stress, the von Mises stress and the parameters of deflection were investigated. The normal stress was generated to examine the distribution of stress on the contact area of PMMA and liner surface. The von Mises stress as a parameter of failure criteria in normal direction was generated to investigate the change of stress along the thickness of PMMA and liner. Deflection was also presented to examine the effect of the coating on the cement mantle. The location of data retrieval is illustrated in Figure 2. Data is taken in each node along lines of data retrieval.

\section{Results}

Figure 3(a) shows the distribution of contact stress on the cement mantle surface as a function of radius. Meanwhile, Figure 3(b) shows the distribution of contact stress on the liner surface due to the layer variation as a function of contact radius. The S22 feature in the post-processing ABAQUS is used to presented the contact stress on the PMMA and liner surface. Based on Figure 3(a) for cement mantle, the highest contact stress occured when using the thickness of addition layer (t1), i.e. about 4.7 MPa. On the other hand, the lowest contact stress occured when using the thickness of addition layer (t5), i.e. about 3.7 MPa. For liner based on Figure 3(b), the highest contact stress 
occured when using the thickness of addition layer (t5), i.e. about $14 \mathrm{MPa}$. In contrast, the lowest contact stress occurred when using the thickness of addition layer (t1), i.e. about $12.5 \mathrm{MPa}$. Based on the previous research, the addition layer with thickness $1 \mathrm{~mm}$ or in

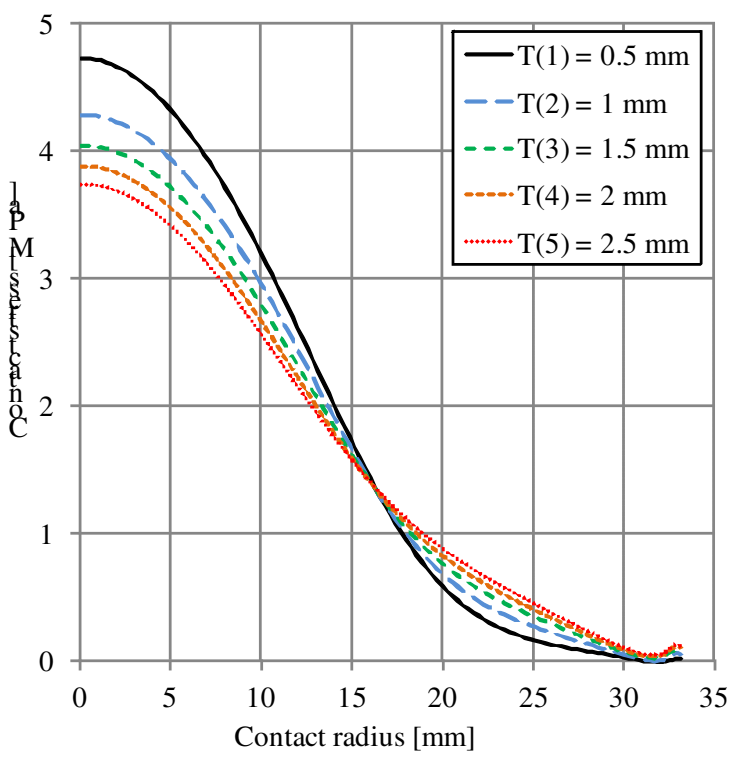

(a) this case refer to $t 2$ was able to reduce the maximum contact stress by about $47 \%$ [9]. In this case, the highest thickness of addition layer was able to reduce the maximum contact stress in PMMA by about 53\%.

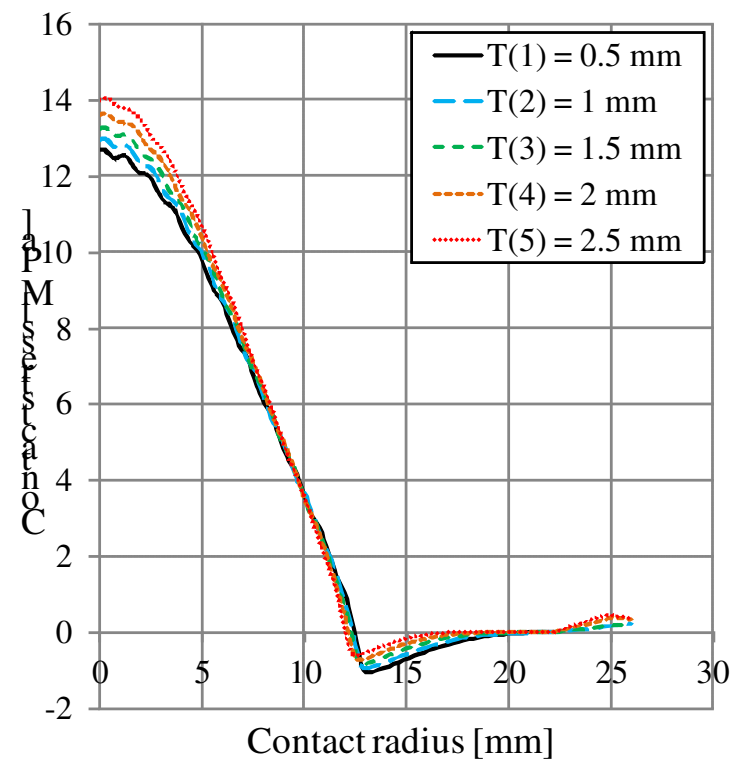

(b)

Fig. 3. Contour plot of contact stress (a) PMMA and (b) liner

Figure 4(a) shows the distribution of von Mises stress on the cement surface as a function of contact radius. Meanwhile, Figure 4(b) present the distribution of von Mises stress on the liner surface due to layer variation as a function of contact radius. The feature of Mises in the post-processing ABAQUS was used to presented the von Mises stress on the PMMA and liner surface. Based on Figure 4(a) for cement mantle, the

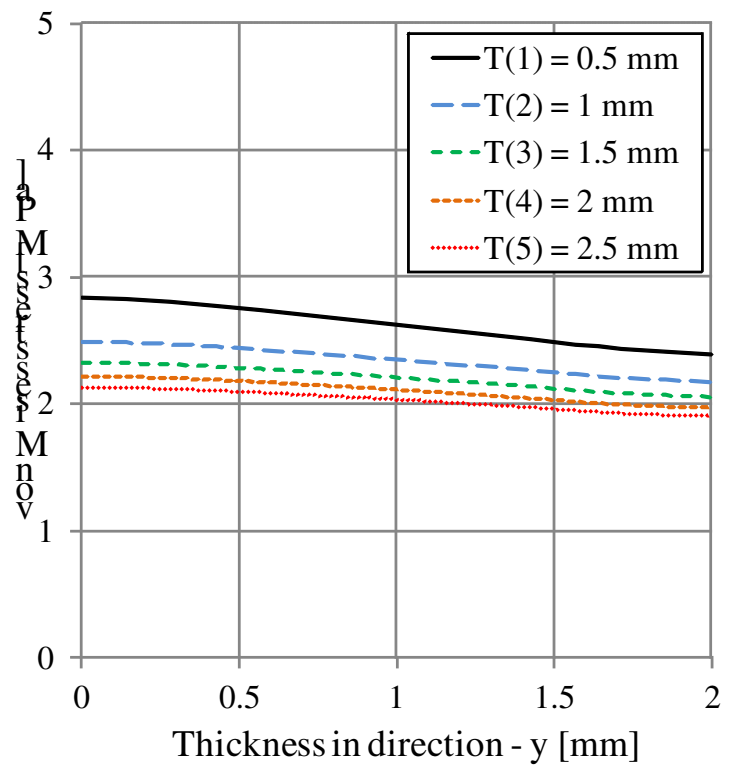

(a) highest von Mises stress occured when using the thickness of addition layer (t1), i.e. about $2.8 \mathrm{MPa}$. In contrast, the lowest von Mises stress occured when using the thickness of addition layer (t5), i.e. about 2.2 $\mathrm{MPa}$. For liner based on Figure 4(b), the highest von Mises stress occured when using the thickness of addition layer (t5), i.e. about 11.2 MPa.

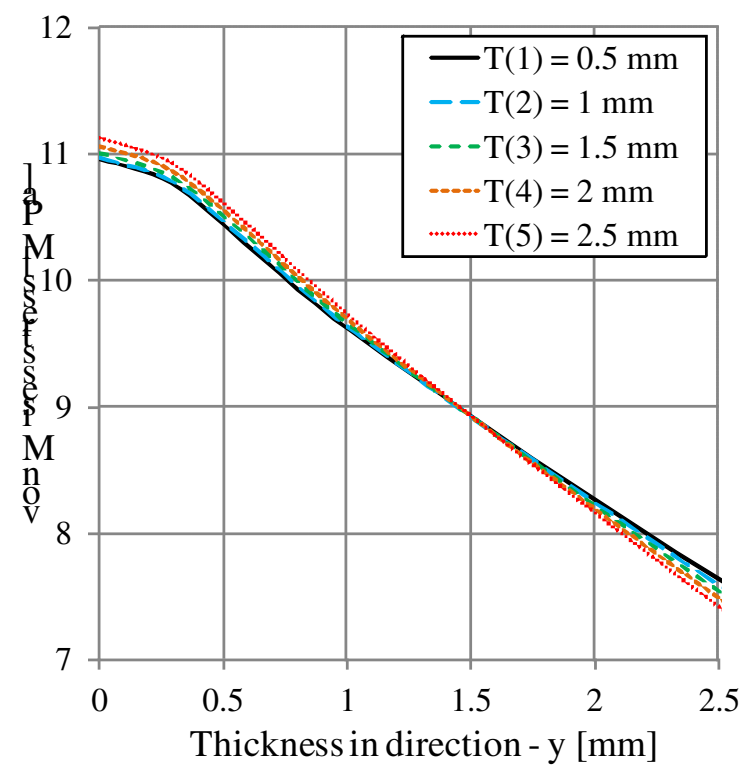

(b)

Fig. 4. Contour plot of von Mises stress (a) PMMA and (b) liner 
On the other hand, the lowest von Mises stress occured when using the thickness of addition layer ( $\mathrm{t} 1$ ), i.e. about 10.9 $\mathrm{MPa}$. Based on the previous research, the addition layer with thickness $1 \mathrm{~mm}$ or in this case refers to $\mathrm{t} 2$ was able to reduce the maximum contact stress by about $61 \%$ [9]. In this case, the highest thickness of addition layer was able to reduce the maximum contact stress in PMMA by about $66 \%$. The maximum von Mises stress in all thickness variation was still within the elastic limit, where the cement material tensile strength around $25 \mathrm{MPa}$ [14-16].

In addition to the contact stress distribution and von Mises stress, the effect of additional layer was evident in the deformation or displacement of the cement mantle relative to the ball. Figure 5(a) shows the

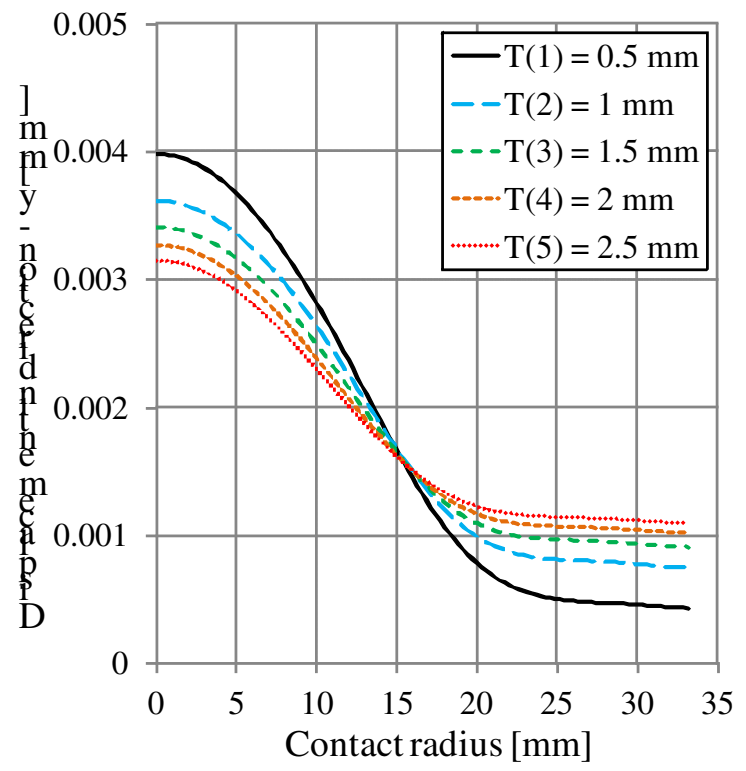

(a) displacement of cement mantle as a function of contact radius. Meanwhile, the displacement of liner is presented in Figure 5(b). The feature of y-direction or U2 displacement in the ABAQUS post-processing was used to present the displacements on cement mantle and surface of liner. Figure 5(a-b) appeared that the position of maximum displacement was at the centre of cement mantle and liner. The maximum displacement on cement mantle was recorded at $0.004 \mathrm{~mm}$ when using $\mathrm{t} 1$, whereas the liner was recorded at $0.0078 \mathrm{~mm}$ when using $\mathrm{t} 1$. These data also showed that the additional layer could decrease the displacement of cement mantle around 60\%. Figures 6(a-b) show the contour plots of contact stress on the cement mantle surface for both models.

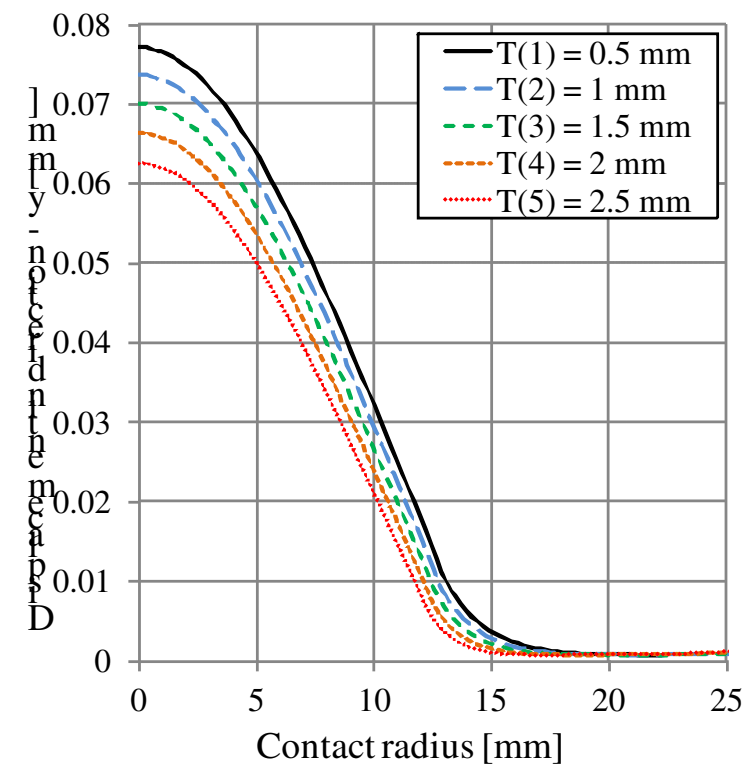

(b)

Fig. 5. Contour plot of displacement in $y$-direction, (a) PMMA and (b) liner

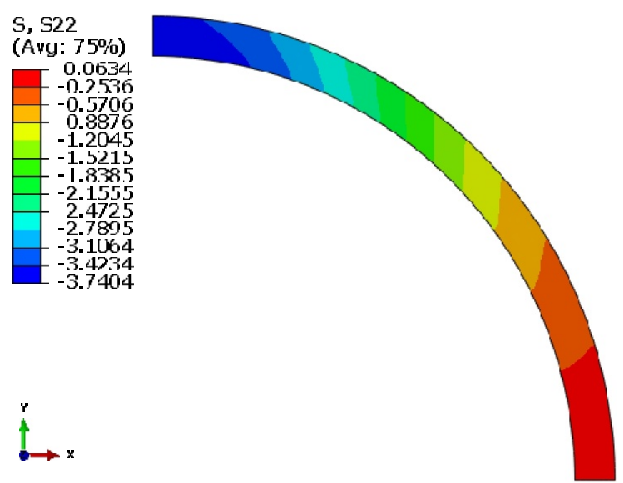

(a)

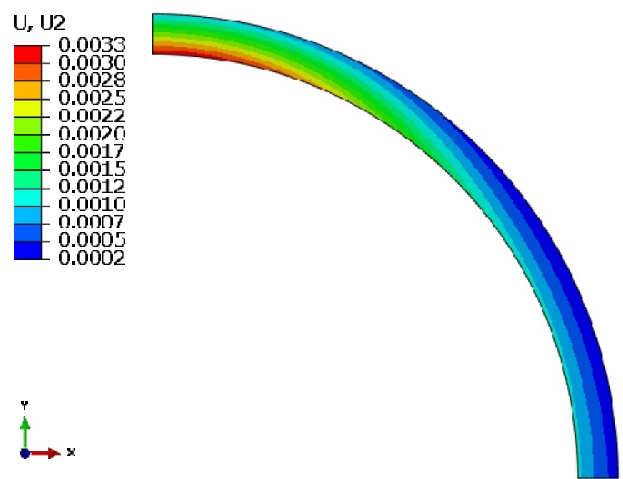

(b)

Fig. 6. Contour plot of cement mantle at t5, (a) contact stress and (b) displacement

\section{Conclusion}

Contact static simulation on the hip prosthetic model with the variations of addition layers was peformed using finite element software. The addition layers in $\mathrm{mm}$ were varied to be $0.5,1,1.5,2$ and 2.5 . The thickness of cement mantle was constant, while the liner thickness followed the changing of the addition layer variation. To examine the effect of layer variation, the stress and deflection of cement mantle and liner were investigated. Results revealed that the highest and lowest stresses for the cement mantle

\footnotetext{
* Corresponding author: ekosaputro984@gmail.com
} 
occured when using the addition layer $0.5 \mathrm{~mm}$ of thickness and $2.5 \mathrm{~mm}$ of thickness, respectively. For liner, the highest and lowest stresses occured when using the addition layer $2.5 \mathrm{~mm}$ of thickness and 0.5 $\mathrm{mm}$ of thickness. Meanwhile, the highest deflection and lowest deflection for the cement mantle and liner were same when using the addition layer $0.5 \mathrm{~mm}$ of thickness and $2.5 \mathrm{~mm}$ of thickness, respectively. In conclusion, the increase in layer thickness will decrease the stress on the cement mantle, whereas the liner is the opposite; the increase in layer thickness will increase the stress. This paper is wished can also manifest the development of life low carbon society to better future country's development.

\section{References}

1. D.A. Fisher, A.C. Tsang, N. Paydar, S. Milionis, C.H. Turner, J. Biomech. 30, 11-12 (1997)

2. C.R. Jacobs, J.B. Bechtel, B.R. Davis, S.H. Naidu, V.D. Pellegrini, Dover, Zimmer Orthopaedic Surgical Products, Inc., (2004)

3. T.J. Letters, R.J.E.D. Higgs, C.A. Baillie, 46th Annual Meeting, Orthopaedic Research Society, March 1215, Orlando, Florida. (2000)

4. N. P. Zant, C. K. Y. Wong, J. Tong, Int. J. Fatigue, 29, 7 (2007)

5. A. Ramos and J. A. Simoes, J Biomech 42, 15 (2009)

6. J. M. S. Lamvohee, P. Ingle, K. Cheah, J. Dowell, R. Mootanah, JCSB, 7, 3 (2014)

7. K. Mann and J. Hertzler, 47th Annual Meeting, Orthopaedic Research Society, February 25-28, San Francisco, California, (2001)

8. J. Hertzler, M. A. Miller, and K. A. Mann, J. Orthop. Res. 20, 4 (2002)

9. J. Jamari, A.L. Han, E. Saputra, I.B. Anwar, E. van der Heide, IJETI, 8, 2 (2018)
10. E. Saputra, I. B. Anwar, J. Jamari, E. van der Heide, Procedia Eng. 68 (2013)

11. J. Jamari, R. Ismail, E. Saputra, S. Sugiyanto, I. B. Anwar, Adv. Mat. Res. 896 (2014)

12. E. Saputra, I. B. Anwar, R. Ismail, J. Jamari, E. van der Heide, Jurnal Teknologi (Sciences and Engineering) 66, 3 (2014)

13. E. Gunn, D. Gundapaneni, and T. Goswami, Biomatter. 2, 2 (2012)

14. A. E. Anderson, C. L. Peters, B. D. Tuttle, and J. A. Weiss, J. Biomech. Eng. 127, 3 (2005)

15. A. Sahli, S. Benbareka, S. Wayneb, B. A. B. Bouiadjraa, and B. Seriera, Appl. Bionics. Biomech. 11, 3 (2014)

16. D. Ouinas, A. Flliti, M. Sahnoun, S. Benbarek, and N. Taghezout, Int. J. Comput. Mater. Sci. Eng. 2, 6 (2012)

17. T. Achour, M. S. H. Tabeti, M. M. Bouziane, S. Benbarek, B. B. Bouiadjra, and A. Mankour, Comp. Mater. Sci. 47, 3 (2010)

18. F. C. Eichmiller, J. A. Tesk, and C. M. Croarkin, in Transactions of the Society for Biomaterials. 27th Annual Meeting, p. 472, (2001)

19. F. Yildiz, A. F. Yetim, A. Alsaran, A. Celik, and I. Kaymaz, Tribol. Int. 44, 12 (2011)

20. ABAQUS Documentation, Dassault Systèmes, Providence, RI, (2012)

21. G. Bergmann, G. Deuretzbacher, G. Heller, F. Graichen, A. Rohlmann, J. Strauss, G. N. Duda, J. Biomech. 34, 7 (2001) 